\title{
A Case Study on Anxiety of University English Teachers as Visiting Scholars in Their Collaborative Learning*
}

\author{
LI Chun-mei \\ Guangdong University of Foreign Studies South China Business College, Guangzhou, China
}

\begin{abstract}
The study is to explore the test anxiety of three university English teachers in their collaborative learning community when they do their visiting scholar program. The research questions are about the representations of test anxiety of the college English teacher collaborative learning community as visiting scholars, and the interaction between anxiety and their collaborative learning. The main data collection includes deep interview, field observation, online chatting, etc. The research finds that at the three stages of their learning, the participant shows various representations of test anxiety from cognitive, affective and behavioral perspectives, and collaborative learning community facilitates the participant have better execution in learning, more pressure released and much cognitive enhancement achieved. In contrast, lack of collaborative learning environment in her working university and the specific anxiety for marriage in female participant are two additional findings in the study, which may prove the positive effect of collaborative learning on anxiety from another point of view.
\end{abstract}

Keywords: anxiety, collaborative learning, university teachers as visiting scholar

\section{Introduction}

Collaborative learning was originated from the Constructivism Learning Theory and with intersubjectivity as its guiding principle. Collaborative learning is a situation in which two or more people learn or attempt to learn something together, based on the model that knowledge can be created within a population where members actively interact by sharing experiences and take on asymmetry roles (Dillenbourg, 1999; Mitnik, Recabarren, Nussbaum \&, Soto, 2009).

Studies on collaborative learning mostly focus on student-student interaction inside the classroom or collaborative networked learning in the virtual world. We could seldom find researches on teacher-teacher collaborative learning, if any, most of which are generally at the level of theoretical discussion rather than empirical exploration.

Researches on collaborative language learning are prosperously developed, while majority of which highlight on the interaction between patterns of collaboration and linguistic performance from cognitive point of

\footnotetext{
* Acknowledgement: The author wishes to acknowledge support from English Language and Literature, a Key Program in Gauangdong Province (GDTX170109), 2017; The Research Team in South China Buisiness College: The Association Project of Comparative Study of English and Chinese in the New Era (2017-298).

LI Chun-mei, Ph.D. of applied linguistics, Associate Professor, English Language and Culture School, Guangdong University of Foreign Studies South China Business College, Guangzhou, China.
} 
view by reference to Vygosky's theory of cognitive development (Watanabe \& Swain, 2007; Storch, 2002, 2009). They put more emphasis on the function of external factors of forms on collaborative learning, yet neglecting that of the internalindividual difference from affective point of view.

The combination of affective variables and collaborative learning has been studied not much and more theoretically and generally (Crandall, 2000). And among all affective variables, anxiety seems to be regarded as the one that most pervasively impedes the learning process. Studies on anxiety are mainly concentrating on the contributing factors of anxiety and the means of reducing anxiety within classroom. Anxiety on adult collaborative learning outside the classroom is rarely explored. Therefore, it is highly necessary to explore how anxiety interacts with the collaborative learning of teachers as visiting scholars.

The goal of this study is to investigate the dynamic function of anxiety in the collaborative learning ofuniversity English teachers as visiting scholars. It is to be a tentative longitudinal case study, exploring how anxiety of the participants changes throughout the different stages in their collaborative learning.

Therefore, the research questions for the study could be as follows:

How is anxiety represented in the different stages of collaborative learning of College English teachers as visiting scholars?

How does anxiety interact with their collaborative learning?

\section{Theoretical Basis}

\section{Collaborative Learning Factors}

Collaborative learning factors have been studied for a long time, and three leading figures in this field are David Johnson \& Roger Johnson, Robert Slavin and Spenser Kagan. They all consider individual accountability as a significant collaborative learning factor. Besides that, positive interdependence, simultaneous and face-to-face promoting interaction, equal opportunity for success/equal participation, interpersonal and small group skills, group goals and group processing are respectively all important factors in collaborative learning.

\section{Test Anxiety}

According to Chen (2010), test anxiety could be analyzed from the following three perspectives: cognitive facet, affective facet and behavioral facet.

From cognitive perspective, we can see worry as the most powerful cognitive factor in test anxiety, indicating the suffering and uneasiness. People with high test anxiety cannot concentrate all their mind on the test task, on the contrary, they focus on the result and effect brought by the failure of meeting the challenge. When individuals believe that they lack of the capability to deal with the test task and are uncertain about the result of the incapability, the cognitive worry come into being. People with high test anxiety are tightly constrained by self-accusation.

From affective perspective, researchers tend to divide it into the actual physiological arousal and the perception to the arousal. Under the test pressure, the most popular arousal mode is autonomic arousal, reflected physiologically by faster heart beating, heavier sweating, stomaching, sense of vomiting, faster breathing, trembling, etc. Since many studies show that the self-report of test anxiety is quite different from the actual physiological arousal in the test context, it's highly necessary to distinguish the actual arousal and the perceived arousal. Therefore the emotionality in this affective dimension is closely related with the one in the cognitive dimension. 
From behavioral perspective, there are two main behaviors for test anxiety: learning and testing skill deficits and study procrastination. People with high test anxiety have defects on all kinds of academic skills, reflecting in the time arrangement in class and tests, organization of class notes, preparation for tests, integration of major content, etc. (Culler \& Holahan, 1980; Kirkland \& Hollandsworth, 1980). And people with high text anxiety come across more difficulties in the test preparation (Benjamin et al., 1981), which may indirectly influence test behavior and achievement. They also delay their studies and are troubled by the delay, for they hate the test content, or they fear for the failure (Solomon \& Rothblum, 1984).

\section{Methodology}

\section{Participants}

Three female university teachers of English participated in the study, who are from three different universities (two from Beijing key universities, the other one from other provincial key university), serving as visiting scholars in one of the best foreign language universities in China for one year. They all applied for Ph.D. program to the Research Centre for Foreign Language Education in that university. With the purpose of preparation for the entrance examination they voluntarily formed a collaborative learning group to read books, share materials and information, discuss about the difficulties encountered in the learning process and encourage each other. Three of them have master's degree, on totally different directions in English, but two of them supervised by and applied for the same supervisor in their visited university. They age from near 30 to near 40, two of them married and one of the two having a family.

Table 1

Basic Information of the Participants

\begin{tabular}{|c|c|c|c|c|c|}
\hline Name & Age & Supervisor & Marriage & Family & Working place \\
\hline S & 39 & W & M & One child & Outside BJ \\
\hline L & 28 & W & Single & no & Beijing \\
\hline Y & 35 & L & M & no & Beijing \\
\hline
\end{tabular}

In recent years, many universities in Beijing stipulate that the teachers without a doctorate are forbidden to be promoted to be assistant professors. Therefore I chose participants from two universities in Beijing, one of which has the above rule and the other not yet but possibly will do so in the near future. And the third participant has not heard such trend in her university. Therefore the participants' age, working and studying background, their state of marriage and family may be the mainstream of the university English teachers who would like to apply for a doctorate.

Another reason why I chose these three participants is that their collaborative learning group is the only one I have heard of and could have access toamong the visiting scholars. Actually, I am the fourth member of the group studying in the same program of the same university with them. We have developed good friendship with each other. As a participant observer, I believe it's easier and more possible to observe and perceive the very subtle and true emotion change of the participants with insider's eye, thus to make the data collection and data analysis of higher validity.

\section{Data Collection}

The study lasted from December 2010 to May 2011 for half a year, during which the researcher did research 
roughly according to the following time frame of the collaborative stages:

- Stage 1: before the entrance examination (2010.12-2011.1)

$\rightarrow$ Sub-stage 1: at university (2010.12)

$\rightarrow$ Sub-stage 2: in winter vacation (2011.1.10-2011.2)

$\rightarrow$ Sub-stage 3: back to university just before examination (2011.2-2011.3.20)

- Stage 2: after the entrance examination before leaving the visited university (2011.4-2011.5)

In Substage 1 of Stage 1, the group was formed and finished the first task-learning a book concerning one of their exam course. Each member was in charge of one part of the book and presented the outline of the part before deadline. And in group presentation and discussion, each part was explained and discussed by different members respectively. The data were mainly collected through audio recording the two group activities, gathering the outlines sent through email box, informal chatting with participants and close observation of their behavior in and after class.

In Substage 2, the data were collected through emails, mobile phone messages, and QQ messages which I telephoned them directly afterwards to verify the messages were sent by themselves rather than someone else. During this period, we planned to learn schools of linguistics together, by distributing each member one key school, providing outline of the main theory and comments on it, and putting all materials and comments together for reference. Unfortunately, this task was only poorly finished.

In Substage 3, the group has no more activities, but interaction between group members still flourish. Therefore data were collected only through interviews and informal chatting with participants, close observation to their daily life, and some interviews with their classrooms, esp. those living with them. And I also collected some of their reflective journals on the collaborative learning.

In Stage 2, he participants did two scales (Beck Anxiety Inventory (BAI) and Test Anxiety Scale (TAI)) immediately after the entrance exam. BAI was created by an American psychiatrist Dr. Aaron T. Beck in 1985, and is a 21-question multiple-choice self-report inventory that is used for measuring the severity of an individual adult's anxiety. TAI was created by American psychologist in the Department of Psychology of Washington University Irwin G. Sarason, which has been one of the most famous and widely used till now. The participants in the study are all adults and the group was formed originally for preparation for the exam, therefore I choose these two scales.

\section{Data Analysis}

Due to the space limit, this paper will only report the data analysis of one participant (L), and the corresponding findings are mainly based on the participant's interview analysis, field observation, emails and text messages with her. Since the two scales are done rather late, scale resultsand other data like her colleague's comment on the participant are served as triangulation.

The audio-recorded interview data in this study are transcribed and coded by the researcher herself. Based on Glaser's Grounded Theory, the researcher coded the data of similar content, and then grouped the similar concepts, trying to generalize some themes, which may partly explain the research questions.

The study tries to investigate from the collected data the changes of anxiety throughout different stages of collaborative learning, mainly focusing on test anxiety, and to explore the correlation and interaction between 
anxiety and collaboration, whether or not collaborative learning among these university English teachers as visiting scholars help reduce their test anxiety, which in turn improve their collaborative learning in the next turn, and how.

\section{Findings and Discussion}

\section{Representation of the Test Anxiety}

The test anxiety of the participant was represented in different ways in three stages:

\section{Before the test.}

(a) Body reaction: the participant felt generally exhausted, including having aching back and cramp leg, curvature of the spine, and sharply impaired vision.

(b) Psychological state and behavior: being absent-minded, trying to avoid, and being procrastinated.

\section{During the test}

(a) Body reaction: extremely sleepy due to the little sleep overnight; no sweating but slow reaction.

(b) Psychological state and behavior: during the first hour, the participant was clear; in the middle hour, she felt absent-mind and she wasted a lot of time; for the last hour, she felt nervous and anxious for lack of time and short of answer. Feeling good when she saw there are some items within her knowledge and ability domain. Almost no anxiety for test difficulty.

\section{After the test}

(a) Body reaction: the participant felt exhausted, and she exerted herself to the most.

(b) Psychological state and behavior: much reflection on her poor testing skills (like bad time arrangement during the test), on lack of book knowledge accumulation and academic capability raising before test, on her lack of sufficient motivation in the exam preparation and sometimes contradictory expectations for the future learning (one is that it is good to go on preparing for another year to have more solid knowledge base, the other is that it is impossible for her to pass the next year exam since there will be more rivals with more capabilities participating), almost all are on negative side, which shows her strong state test anxiety.

From the above test anxiety presentation, it is not difficult for us to perceive the relatively negative influence of test anxiety on the learning and performance of the participant, and the main features of adult test anxiety, which seem to cover the three facets of text anxiety (cognitive facet, affective facet and behavioral facet) evenly.

\section{Collaborative Learning Effect on Test Anxiety}

Foundation/background of collaborative learning group. The three participants are all visiting scholars in the same research center for foreign language education, and three of them all appreciated and enjoyed the very free and positive atmosphere there for academic discussion and daily communication, where they felt encouragement from peers and teachers to help and share, which makes them richer and happier.

Furthermore, they also have the collaborative experience in doing group presentation in the same course, which is one of the most important courses in the entrance examination for Ph.D. program they all would take the next spring, then a collaborative learning group was naturally formed by three of them to facilitate their learning.

Therefore, the common group goal was very obvious from the original intention of the collaborative learning group for preparing entrance examination for Ph.D. program. And the simultaneous and face-to-face promoting interaction was made possible since they studied in the same research center in the same university. 
They believe they have equal opportunity for success in that the entrance examination for Ph.D. program is a national examination fair enough to all qualified participants around the whole country.

Positive effect of collaborative learning on anxiety. From the remarks in the interview and other data, the participant mentioned the following positive effects of their collaborative learning:

(1) Better execution

The first and foremost effect from collaborative learning group for the participant $\mathrm{L}$ is that she perceived she had better execution on her learning plans than before.

I was rather slow and was not so urgently to do anything. But now I felt being supervised and pushed by them, sometimes I was even pulled forward by a kind of implicit power since I knew their schedule and execution of their study plan. (L interview 1)

In a way, from behavioral perspective, study procrastination of the participant was alleviated through peer encouragement and pressure in the collaborative learning group.

(2) More pressure released

The second and psychologically positive effect of the collaborative learning is to help ease the pressure in achieving learning and working tasks,

I could complain very often with the other two members about the learning difficulties and troubles at work, since we share the same experience and I knew they could understand me. I could always get theirechoes, sympathy and encouragement. I felt a kind of relief after I talked to them. (L interview 3)

This occurred before the exam and more in the post-test period. From her anxiety representation (total collapse and much reflection) after the test, we could analyze that she suffered high anxiety right after the test. However, she talked to the peers in the group and felt a relief and could even start to prepare for the exam next year, which shows her anxiety released. And the follow-up information about participant $\mathrm{L}$ is that she did pass the exam the next year.

(3) Cognitive enhancement

Another important effect mentioned by $\mathrm{L}$ is that she acquired great progress in learning with her group mates.

I got their guidance and advice in SLA knowledge, in applied linguistic research method, in critical thinking ability through group discussion; and they also shared numerous learning resource with me, which broadened my vision and expanded my outlook in this field. (L interview 2)

Therefore, collaborative learning may lessen the cognitive anxiety in dealing with the test task and learning difficulty. From L's anxiety representation during the test, we could find that there is no anxiety for test difficulty, while much of the anxiety is about the arrangement of time.

Negative effect by collaboration vacancy. An old Chinese poem says "No water's enough when you have crossed the sea; No cloud is beautiful but that which crowns the peak” (by Yuan Zhen in Tang Dynasty, translated by Xu Yuanchong). Participant L seems to have an extremely sharp and strong contrast between the enjoyable collaborative atmosphere in the center she visited and the desperate discouraging academic atmosphere in her department, especially at her second semester as a visiting scholar in the center and a team member in the collaborative learning group. She described her present working and learning state as being plunged in a 
“quagmire” (泥潭 in Chinese), i.e. a difficult perplexing situation with the colleagues around her all dragging her down rather than pulling her out, from experienced professors therefore looking down upon her, to the once-intimate friends but full of sarcastic and ironic communication now. The more efforts she made in the visiting center, and the more willingly she would communicate academic issues with her colleagues and friends, the more contemptuous response she felt she got. The more she is willing to getting out of the quagmire, and the more efforts she makes to do so, the more she felt she fell down into it. This dilemma aggravated her anxiety and made her desperate and quit communication in that surroundings.

Main features of adult collaborative learning. From the above analysis and the interview transcript, the main features of adult collaborative learning could be generalized from two dimensions. From academic and cognitive dimension, knowledge delivering and resource sharing could be found in major part of their collaborative learning. And through group discussion, critical thinking guiding is also of frequent occurrence. Both could lessen their test anxiety since the participant felt cognitive enhancement. From psychological and emotional dimension, peer encouragement can help release the test pressure, while deadline of reading club and other learning activities, and peer academic achievement is like a double-edged sword, which may both increase the participant stress and motivate her make more effort.

\section{Additional Findings}

Marriage anxiety. The particular individual feature of test anxiety for this participant is her marriage anxiety, which seems to have so much effect on her that she covers a lot of pages to talk about it and analyze it. However, marriage is a very specific case with too much individual difference, I could only present this additional anxiety appearing in this test anxiety study as an additional finding.

As she analyzes, her demotivation in preparation and high test anxiety could be attributed to her worry that the coming Ph.D. program may damage her beauty and delay or even impede her future marriage. On one hand, her family members seem to be against her doing the program; on the other hand, her friends hold quite opposite stance. She hesitated for a period of time, and finally made a firm decision by citing Steven Jobs' saying "to follow your heart”.

Marriage anxiety could reflect the social influence on the participant, esp. women participants when they confront with decisive professional choices.

\section{Conclusion}

Changing in the world is absolute, and human beings are no exception as part of the world. Therefore we either choose to have an active change by ourselves and/or to be changed by others, i.e. a kind of reflection and representation of its subjectivity and intersubjectivity. Learning would be throughout all one's life, teachers are no exceptions. Collaborative learning community helps to enhance their knowledge accumulation and critical thinking ability, form an affective link among teachers in learning and helps to reduce some negative emotions like anxiety, and furthermore, their long-term collaborative relation may maintain with their friendship.

Over a long period of time, some sense of reliance and belief come into being among the group members and they benefit from encouragement with each other, which may facilitate their cognitive and psychological growth. The specific features of university teachers seem to require teachers to break the isolation and form a relatively long collaborative learning group with other teachers for further sustainable development of their own. 
Due to the space and my research limit, this paper only focuses on one participant's anxiety, and some of her data were collected at not proper time, like the two scales. In the future research, I will try to explain why she emphasized more on collaborative help on psychological dimension in her interview, and need to analyze the other two participants' interview transcript and other data to confirm and triangulate the statement in this paper.

\section{References}

Crandall, J. A. (2000). Language teacher education. Annual Review of Applied Linguistics, 20, 34-55.

Culler, R. E., \& Holahan, C. J. (1980). Test anxiety and academic performance: The effects of study-related behaviors. Journal of Educational Psychology, 72, 16-20.

Dillenbourg, P. (1999). Collaborative learning: Cognitive and computational approaches. Advances in learning and instruction series. New York, NY: Elsevier Science, Inc.

Chen, H. L. (2010). Test anxiety in language testing situations. Hangzhou: Zhejiang University Press.

Gao, Y. (2001). A study on the classification, research and application in the classroom. Education Review, (2), 14-17

Gao, Y., Li, C., \& You, T. Z. (2001). The meta-analysis on collaborative learning. Contemporary Education Sciences, (10), 19-21.

Kirkland, K., \& Hollandsworth, J. G. (1980). Effective test taking: Skills-acquisition versus anxiety-reduction techniques. Journal of Consulting \& Clinical Psychology, 48(4):431-9.

Li, J. L. (2008). Learning community: The effective approach for teacher professional development. Education Exploration, (10), 101-102.

Ma, L., \& Sheng, Q. L. (2008). What on earth contributes to collaboration-The comparison between the contributive factors for collaboration. Research in Educational Development, (18), 29-34.

Mitnik, R., Recabarren, M., Nussbaum, M., \& Soto, A. (2009). Collaborative robotic instruction: A graph teaching experience. Computers \& Education, 53(2), 330-342.

Navehbenjamin, M., Mckeachie, W. J., Lin, Y., et al. (1981). Test anxiety: Deficits in information processing. Journal of Educational Psychology, 73(6), 816-824.

Solomon, L., \& Rothblum, E. (1984). Academic procrastination: Frequency and cognitive-behavioral correlates. Journal of Counseling Psychology, 31, 503-509.

Storch, N. (2002). Patterns of interaction in ESL pair work. Language Learning, 52, 119-158.

Storch, N., \& Wigglesworth, G. (2009). Pair versus individual writing: Effects on fluency, complexity an accuracy. Language Testing, 26(3), 445-466.

Watanabe, Y., \& Swain, M. (2007). Effects of proficiency differences and patterns of pair interaction on second language learning: collaborative dialogue between adult ESL learners. Language Teaching Research, (4), 121-142.

Wang, J. H., Yang, F. Q., \& Han, H. M. (2010). Collaborative learning: The effective approach for teacher professional development. Journal of Hebei University (Philosophy and Social Science), (4), 49-50.

Wang, T. (2005). A brief analysis on the theoretical basis of collaborative learning. Curriculum, Teaching Material and Method, (1), 30-35.

Wang, T. (2002). On the basic theory of collaborative learning. Educational Research, (2), 68-72.

Wang, T. (1999). The basic types and theoretical analysis on collaborative learning. Contemporary Education Science, (12), 8-12.

Wu, D. J. (2004). The collaborative learning strategies of teacher education. China Educational Technology, (7), 21-25. 